\title{
Term Structure and Interest Rate Stabilization Policies in the Greenspan Era
}

\author{
Anna Florio* \\ Politecnico di Milano
}

\begin{abstract}
Previous studies attribute the failure of the expectations theory, using the 6-3 month Treasury bill spread, to the Federal Reserve's commitment to stabilizing interest rates. We find that with the advent of Greenspan, this spread predicts future changes in the short rate in the United States. This success can be explained by interest rate smoothing and greater transparency by the Fed. By enhancing the management of market expectations and reducing uncertainty, the central bank improves interest rate predictability and gains credibility from the market, as lower term premia suggest.

Jel classification: E43; E52.

Keywords: Monetary Policy; Term structure; Federal Reserve; Expectation theory.

*Department of Management, Economics and Industrial Engineering, Politecnico di Milano, via Lambruschini 4, 20156. Milan, Italy.

Tel.: +39-02-2399-2754; fax: +39-02-2399-2710

E-mail address: anna.florio@polimi.it (A. Florio)

orcid: 0000-0002-5280-6490
\end{abstract}

This is the peer reviewed version of the article accepted for publication in Empirical Economics. The version of record (Florio, A. (2020) "Term structure and interest rate stabilization policies in the Greenspan era," Empirical Economics, 59, 345-355) is available online at: https://link.springer.com/article/10.1007/s00181-019-01672-x.

This article may be used for non-commercial purposes in accordance with Wiley Terms and Conditions for Use of Self-Archived Versions. 


\section{Introduction}

In their pioneering article, Mankiw and Miron (1986) noted that with the founding of the Federal Reserve, the short rate became a random walk, hence less predictable. They attributed the failure of the expectations theory (using 3- and 6-month Treasury bill rates), from the establishment of the Fed to 1979, to the central bank's commitment to stabilizing interest rates. Two years later, Kugler (1988) confirmed this failure in the years 1974-1986 for the United States, but not for Switzerland and Germany, whose central banks did not attempt to stabilize interest rates. According to Fuhrer (1996), the rejection of the expectations theory was due to shifts in monetary policy regimes that, by changing Fed behaviour, modified the short-term interest rate generating process.

We check whether the rejection of the expectations hypothesis (documented by Campbell 1995) is confirmed during the Alan Greenspan tenure, and if not, whether the Fed's changing behaviour over time could have been responsible for the enhanced short rate predictability.

Using the 6-3 month Treasury bill spread for the United States, we confirm the rejection of the expectations hypothesis for the pre-Greenspan period, but not for the Greenspan era, especially starting from the year 1989, when the Fed began to smooth interest rates. Short rate predictability, however, is found to break down when policy rates were moved aggressively.

The paper is structured as follows. The next section briefly reviews the expectations theory. Section 3 tests it using U.S. data on 3- and 6-month Treasury bill rates for the period 1959-2007, which excludes, on purpose, the turbulent years of the recent global financial crisis. Section 4 examines if and how the stochastic process of the short rate changed, and Section 5 uses these results to focus on the Greenspan-Bernanke period. Some theoretical considerations about the effects of interest smoothing and greater transparency on interest 
rates' predictability are reported in Section 6 . Section 7 concludes.

\section{The expectations theory of the term structure}

According to the expectations theory of term structure, the return from investing in a two-period bill $\left(R_{t}\right)$ is equal to the average of the yield from the current $\left(r_{t}\right)$ and the expected $\left(E_{t} r_{t+1}\right)$ one-period bill plus a constant term premium $(\theta)$ :

$$
R_{t}=\frac{1}{2}\left(r_{t}+E_{t} r_{t+1}\right)+\theta
$$

Alternatively:

$$
\left(E_{t} r_{t+1}-r_{t}\right)=2\left(R_{t}-r_{t}\right)-2 \theta
$$

which links the expected change in the short rate (on the left side) to the longshort rate yield spread (the first term on the right side). Below, we test if the spread rationally forecasts the future path of the short rate. With rational expectations, we have:

$$
r_{t+1}=E_{t} r_{t+1}+v_{t+1}
$$

Hence, inserting (3) into (2), the relationship to be tested becomes:

$$
\left(r_{t+1}-r_{t}\right)=\alpha+\beta\left(R_{t}-r_{t}\right)+v_{t+1}
$$

where $\alpha=-2 \theta$ and $\beta=2$. Under the null hypothesis of rational expectations, the error term is orthogonal to the regressors, and OLS yields consistent estimates of the coefficients. 


\section{Empirical evidence of the spread's predictive power}

We test the term structure of interest rates at the short end of the maturity spectrum using monthly data for U.S. 3- and 6-month Treasury bill rates, taken from the St. Louis Fed database, for the period 1959-2007.

We split the sample into a pre-Greenspan period (1959:1-1987:7) and a Greenspan-Bernanke period (1987:8-2007:12). For the first, we identify three different subperiods: (part of) the McChesney Martin (1959:1-1970:1), the Burns and Miller (1970:2-1979:7) and the Volcker (1979:8-1987:7) tenures. We split this last subsample further to separate the 1979:8-1982:9 years, when Volcker's anti-inflationary policy targeted monetary aggregates. Results from the estimates of equation (4) are given in Table 1.

For the pre-Greenspan period, we do not find support for the expectations hypothesis: although positive, the coefficients of the spread are, for the whole sample and for each subsample, not significantly different from zero and are significantly lower than the theoretical value of 2 , while the constant is never significantly different from zero. The low R-squared (never greater than 0.03) reinforces the claim of negligible predictive power of the spread.

However, for the Greenspan-Bernanke tenure, the coefficient of the spread is significantly different from zero, but not significantly different from 2 , and the R-squared is an order of magnitude larger compared to those of the previous periods. Thus, from Greenspan onward, short rates rise when the long-short term spread is high, in conformance with the expectations hypothesis. 


\section{The stochastic process of the short rate}

The empirical evidence above is consistent, for the pre-Greenspan period, with Mankiw and Miron's result (1986) of no predictive power for future short-term interest rate changes until 1979. In their opinion, the rejection of the expectations theory was a consequence of the commitment of the Fed to stabilizing interest rates, resulting in random walk behaviour for the short rate. However, since interest rate stabilization remains a Fed goal, why did the short rate become predictable with the advent of Greenspan? We think the explanation can be found in the reduced volatility of the Fed target rate (and, consequently, of the other shorter rates).

Consider the change in the daily federal funds target rate starting from October $1982^{1}$ (see Fig. 1): the vertical line in 1989 signals a change in the behaviour of this series. While pre-1989 target changes came in multiples of 0.0625 percentage points and varied considerably, since 1989, the Fed has moved its target only by 0.25 or 0.50 percentage points (only on two occasions in the sample did it make a movement of 0.75). Furthermore, after this year, reversals become more infrequent: in the six-year span between 1982 and 1988, there were 17 reversals, but just 9 in the following 18 years. After 1989, the central bank improved the private sector's learning, reducing interest rate reversals thanks to interest rate smoothing (see Ellison 2006).

A Chow test for the federal target rate series with 1989 as a known breakpoint confirms a structural shift (with a p-value of 0.036). Moreover, though the presence of a unit root in the Fed target process cannot be rejected, the variance of its innovation decreases after 1989, when even the other reference short rates (i.e., the federal funds rate and the 3-month Treasury bill rate) show lower

\footnotetext{
${ }^{1}$ The start date is chosen to exclude the strict monetary targeting regime during Volcker's tenure. Previous years were not included due to a lack of data availability.
} 
volatility (see Table 2). ${ }^{2}$ A Breusch-Pagan test rejects the null of homoskedasticity in the residuals from an $\mathrm{AR}(1)$ model for the federal funds target rate when a dummy for the post-1989 years is included. The coefficient associated with this dummy is significant and negative, signalling a reduction in volatility, even when the federal funds rate or the 3 -month Treasury bill rate is employed. ${ }^{3}$

Moreover, the Greenspan era signals the beginning of the disclosure of the "Secrets of the Temple": ${ }^{4}$ over these years, the Fed substantially increased transparency about its policy decisions. It decided, beginning in February 1994, to announce the new target at the end of each Federal Open Market Committee (FOMC) meeting, whose calendar was made public in advance, and to provide post-meeting statements describing its policy action. At the start of 2000, the FOMC decided to provide such statements immediately after each meeting, whether or not it changed policy, and to include an assessment of the risks to the economic outlook. Since 2004, the Fed, as well as providing a forecast of core inflation, has sped up the release of the FOMC minutes to a three-week lag. These steps, by decreasing market uncertainty, have helped markets predict future monetary policy actions (see Swanson 2006).

We apply a Bai-Perron (1998) multiple breakpoint test to check if the dates for the beginning of interest smoothing by the Fed (1989) and those that signal the crucial steps towards greater transparency $(1994,2000,2004)$ are confirmed as breakpoints in the (change of the) federal target rate series. As Table 3 shows, the maximized statistics indicate the presence of breaks exactly in the expected dates. ${ }^{5}$

\footnotetext{
${ }^{2}$ We find the federal target rate to still be a random walk whose innovations, however, have changed, becoming more predictable. Note that, since the series is a random walk, the graphical representation of residuals from the regression of the target on a constant and its first lagged value would be almost indistinguishable from those in Figure 1.

${ }^{3}$ Results, omitted for brevity, are available from the author upon request.

${ }^{4}$ This is the evocative title of William Greider's 1987 bestseller about the Federal Reserve.

${ }^{5}$ A Quandt-Andrews unknown breakpoint test finds the single breakpoint to be in 2004:3.
} 


\section{A focus on the Greenspan-Bernanke period}

The lower volatility of short-term rates, together with the evolving steps towards transparency and the change in the stochastic process of the federal funds rate, since 1989, could have contributed, reducing uncertainty, to increasing the predictability of future short rates. Testing the expectations hypothesis using data starting from the end of 1989 further improves the results for the GreenspanBernanke period. As Table 4, Panel A, shows, the estimate for the period 1989:11-2007:9 gives a coefficient on the spread exactly equal to 2, thereby verifying the validity of the expectations hypothesis.

To check this result's robustness, we run a series of OLS regressions, keeping the end of the sample fixed while moving the initial date one month ahead at every step. A given point on the bold line in Fig. 2 shows the value for the coefficient $\beta$ from equation (4) for the regression that spans from that point to the end of the sample. ${ }^{6}$ The dotted lines give the confidence interval at $5 \%$ for the null of $\beta=2$. Fig. 2 shows that the yield spread's coefficient is significantly different from 2 when we take the years from the end of 1994 to (approximately) 2002 as the start of the sample.

We argue that this result should not be read as a failure of the rational expectations hypothesis. Fuhrer (1996), to reconcile the expectations hypothesis with the data, employs "time varying monetary policy to explain what others have explained with time varying term premiums"(p. 1185). We think that these two explanations are not mutually exclusive: by improving the conduct of monetary policy through greater interest rate smoothing and transparency, the central bank has reduced uncertainty. This fact, in turn, could have changed term premia, causing a rejection of the pure expectations hypothesis (which, instead, assumes constant risk premia across different periods). Furthermore,

\footnotetext{
${ }^{6}$ We do not report results for regressions with too few observations; hence, the last starting date considered is 2005:9.
} 
if the validity of the expectations theory for the Greenspan-Bernanke period depends on the larger predictability of interest rates changes, we should look for breakpoints in the estimation of the spread predictive power in those periods when policy rates were moved aggressively, thus surprising the market.

Guided by Fig. 2, we detect one of these periods in 1994:11, when Greenspan aggressively raised the Fed target rate, and another in the years 2001-2002, characterized by large and frequent interest rate cuts to contrast the burst of the dotcom bubble, the impending recession and the Twin Towers attacks. ${ }^{7}$

In the presence of structural breaks, we expect the parameters of term structure equations to not be policy invariant. To check for this possibility, we run a Chow stability test for equation (4), employing data for the Greenspan-Bernanke period and choosing as known breakpoints 1989:11, 1994:11 and 2002:11. The first date marks the beginning of interest rate movements as multiples of 25 b.p., the second the exceptional interest rate rise of 75 b.p. and the third the end of the series of 50 b.p. cuts in 2001-02. A Chow test provides evidence at the $1 \%$ level of a break in these dates (see Table 4, Panel B). Panel C shows the results for the regressions of the changes in the 3-month rate on the 6-3 month spread for the subperiods identified by breakpoints.

Once breakpoints are accounted for, the validity of the expectations theory is confirmed within each subsample: for every subperiod, we obtain an R-squared of approximately 0.34 , as well the maximum statistical significance for the spread coefficients, not statistically different from 2 . The term premium, given by the opposite of half of the constant term (see equation (4)), is always significant and with the right sign. Moreover, it decreases along the three subperiods, from 0.16 in the first period to 0.14 in the second (as Favero and Mosca (2001) find for the

\footnotetext{
${ }^{7}$ Swanson (2006), analysing the same period, introduces a variable named "momentum" that signals uncertainty created by rapid changes in the Fed target rate; he finds that this variable spiked in 2001-2 and 1994-95. Even a Bai-Perron multiple breakpoint test finds the years 1994 and 2002 among the possible breakpoints. Results, not reported for brevity, are available from the author upon request.
} 
years 1994-1999) and 0.07 in the more recent period. This drop is consistent with lower interest rate variability and with the increasing transparency by the Fed that spurs its credibility. ${ }^{8}$

\section{Some theoretical considerations and a caveat}

According to previous literature, the failure of the expectations theory in the pre-Greenspan era was due to the central bank's commitment to stabilizing interest rates. However, even though interest rate stabilization remained a Fed goal, we detect an improved predictability for the short interest rate after the advent of Greenspan. This increased predictability has been related to two additional factors: the pursue of an explicit interest-rate-smoothing goal and greater transparency. This section briefly examines how these two factors can help interest rate predictability.

Woodford (1999), using a New Keynesian forward-looking model, includes an interest rate stability goal in a otherwise traditional central bank loss function. He finds an optimal policy rule that involves current variables and interest rate smoothing. He concludes that, if the central bank wants to acquire credibility, it should commit to a rule that depends on past conditions as well.

What happens if an explicit interest-rate-smoothing goal is added to that loss function? Florio (2009) addresses this point and finds a similar reaction function that, however, depends on expected future interest rates too. In a forward-looking environment, agents' decisions depend on future expected policy rates, but even central bank's decisions depend, in the meantime, on expected future rates. ${ }^{9}$ Moreover, as Fuhrer (1996) asserts, market participants

\footnotetext{
${ }^{8}$ According to Caporale and Caporale (2003), in the U.S., the reduction in interest rate uncertainty brought about by the establishment of the Fed lowered financial market risk, causing a decrease in the risk premium a 6-month instrument pays over a 3-month one from 0.65 before the Fed founding to 0.3 for the period 1914-1933.

${ }^{9}$ Bernanke (2004) stesses this point comparing monetary policy to driving a car whose
} 
use their estimates of the central bank reaction function to forecast short-term nominal rates and to determine, according to the expectations hypothesis, longterm rates. As a consequence, if the central bank improves transparency by disclosing the coefficients in its reaction function, economic agents could more easily gauge the central bank's expected future interest rate. ${ }^{10}$ With smoothing and transparency the central bank aligns its expectations with the private sector's ones, making the path of future interest rates more predictable and, hence, monetary policy more effective.

A well-known but still unsolved issue is whether the decline in interest rate volatility and, in general, in macroeconomic volatility during the Great Moderation years could be ascribed to good luck, good policy or both. According to the first interpretation, this could be due to smaller shocks hitting the economy in those years. In contrast, the good policy view assumes that central bankers have been better equipped to manage monetary policy, owing to their improved ability to affect market expectations and to their increased credibility. While this paper supports the good policy view, the good luck hypothesis is not investigated and this is obviously a limitation of the paper.

\section{Conclusions}

If the rational expectations theory of the term structure holds, the long-short rate spread should predict future changes in the short rate. Using the 6-3 month Treasury bill spread, we find such a predictive power for the Greenspan tenure.

This evidence contrasts with previous analyses that, using the same data for earlier postwar periods, rejected the rational expectations theory of the term

speed "depends not on the pressure on the accelerator at that moment but rather on the expected average pressure on the accelerator over the rest of the trip."

${ }^{10}$ In Florio (2009)'s reaction function, the expected future interest rate becomes predictable since it depends just on values of current and past economic variables. Conversely, in Woodford (1999), it would depend on future (thus unknown) values of the variables. 
structure. Rudebusch (2002), for example, found no information usually available in financial markets for predicting the change in the funds rate 3-6 months out and took this as evidence against the existence of policy inertia: interest rate smoothing would generate predictable future changes in the policy rate that should be embodied in the term structure. Our result for the Greenspan period reduces this inconsistency.

The validity of the term structure at the short end of the maturity spectrum is here attributed to the Fed's behaviour. From Greenspan on, the central bank has minimized interest rate reversals, reduced the variability of interest rate changes and increased transparency in order to make policy more predictable. This behaviour has made it possible for the central bank to reach at least two goals: it reduces uncertainty, thus acquiring credibility from the market (which now asks for lower term premia), and it improves the management of market expectations (which is confirmed by the information content of the yield spread for predicting future changes in the short rate). This last result is a crucial goal for the conduct of monetary policy since, by shaping market expectations, the central bank affects long-term interest rates and thus increases policy effectiveness. 


\section{References}

Bernanke B (2004) The Logic of Monetary Policy. Remarks before the National Economists Club, December 2.

Campbell John Y (1995) Some Lessons from the Yield Curve. J Econ Perspect 9: $124-52$.

Caporale B, Caporale T (2003) Investigating the effects of monetary regime shifts. The case of the Federal Reserve and the shrinking risk premium. Econ Lett 80: 87-91.

Ellison M (2006) The learning cost of interest rate reversals. J Monet Econ 53, 1895-1907.

Favero C, Mosca F (2001) Uncertainty on monetary policy and the expectations model of the term structure of interest rates. Econ Lett 71: 369-75.

Florio A (2009) Asymmetric preferences for interest rate variability and nonlinear monetary policy inertia. Scot J Polit Econ 56: 685-704.

Fuhrer Jeffrey C (1996) Monetary Policy Shifts and Long-Term Interest Rates. Q J Econ 111: 1183-1209.

Greider W (1987) Secrets of the Temple: How the Federal Reserve Runs the Country. New York: Simon and Schuster.

Kugler P (1988) An empirical note on the term structure and interest rate stabilization policies. Q J Econ: 789-92.

Mankiw N G and Miron Jeffrey A (1986) The Changing Behavior of the Term Structure of Interest Rates. Q J Econ 101: 211-28.

Newey Whitney K West Kenneth D (1987) A simple positive semi-definite, heteroskedasticity and autocorrelation consistent covariance matrix. Econometrica 55: 703-8.

Rudebusch Glenn D (2002) Term structure evidence on interest rate smoothing and monetary policy inertia. J Monet Econ 49: 1161-87. 
Swanson E (2006) Have increases in Federal Reserve transparency improved private sector interest rate forecasts? J Money Credit Bank 38(3): 791-819.

Woodford M (1999) Optimal monetary policy inertia. Manch Sch Supplement: $1-35$. 
Table 1 The predictive power of the spread

\begin{tabular}{|c|c|c|c|c|c|c|}
\hline \multirow[t]{2}{*}{ Pre-Greenspan } & 1959:1-1987:7 & 1959:1-1970:1 & 1970:2-1979:7 & $1979: 8-1987: 7$ & $1979: 8-82: 9$ & 1982:10-87: \\
\hline & & McChesney Martin & Burns-Miller & Volcker & & \\
\hline$\alpha$ & $-0.09(0.13)$ & $-0.01(0.1)$ & $-0.12(0.21)$ & $-0.18(0.3)$ & $-0.21(0.71)$ & $-0.16(0.19)$ \\
\hline$\beta$ & $0.66(0.42)$ & $0.5(0.46)$ & $0.93(0.6)$ & $0.5(0.59)$ & $0.49(0.73)$ & $0.49(0.66)$ \\
\hline$R^{2}$ & 0.016 & 0.02 & 0.03 & 0.00 & 0.00 & 0.00 \\
\hline
\end{tabular}

Greenspan-Bernanke 1987:8-2007:9

$\begin{array}{lll}\alpha & -0.22^{* *} & (0.06) \\ \beta & 1.76^{* *} & (0.39) \\ R^{2} & 0.29 & \end{array}$

NOTE: Newey-West standard errors are in parentheses. $(*)$ and $(* *)$ denote significance at the $5 \%$ and $1 \%$ levels, respectively. Model: $\left(r_{t+1}-r_{t}\right)=\alpha+\beta\left(R_{t}-r_{t}\right)+v_{t+1}$, where $r_{t}=3$-month Treasury bill, $R_{t}=6$-month Treasury bill. For the Greenspan-Bernanke period we used data up to 2007:12; here and in the other tables (unless not specified) the adjusted sample is reported.

Table 2 Residuals' standard deviation from AR(1) model

$\begin{array}{ccc} & \text { Pre-1989 } & \text { Post-1989 } \\ \text { Federal funds target rate } & 0.05 & 0.03 \\ \text { Federal funds rate } & 0.36 & 0.18 \\ & & 0.19\end{array}$

NOTE: Monthly data (except for the federal target rate, for which daily data, starting from 1982:10, are used). Residuals' s.d. from the model $r_{t}=\alpha+\beta r_{t-1}+v_{t}$ for the period 1959:12007:9, with $r_{t}$, in turn, being the rates reported in the first column. 
Table 3 Multiple breakpoint tests. Sample 1982:10-2007:12

UDmax determined breaks: 1

WDmax determined breaks: 4

$\begin{array}{lllll}\text { Breaks } & \text { F-stat } & \text { Scaled F-stat } & \text { Weighted F-stat } & \text { Critical value } \\ 1^{*} & 7.22 & 14.44 & 14.44 & 11.47 \\ 2^{*} & 7 & 14.01 & 16.49 & 9.75 \\ 3^{*} & 6.62 & 13.25 & 18.17 & 8.36 \\ 4^{*} & 7.19 & 14.39 & 22.95 & 7.19 \\ & & & & \\ \text { UDMax stat } & & & & \end{array}$

Estimated break dates:

1: $2004: 3$

2: 2000:6, 2004:3

3: 1994:2, 2000:6, 2004:3

4: 1989:6, 1994:2, 2000:6, 2004:3

Note: Bai-Perron tests of 1 to M globally determined breaks for the AR(1) model of the federal target rate. Breaking variables: c fedtarget(-1). Break test options: Trimming 0.15, Max. breaks 4, sign. level 0.05. Test statistics employ HAC covariances (Bartlett kernel, Newey-West fixed bandwidth) and allow heterogeneous error distributions across breaks. Significant at the 0.05 level. ** Bai-Perron (2003) critical values. 
Table 4 Panel A: The predictive power of the spread

$\begin{array}{ll}\text { Greenspan-Bernanke period } & 1989: 11-2007: 9 \\ \alpha & -0.26^{* *}(0.06) \\ \beta & 2.04^{* *}(0.38) \\ R^{2} & 0.34\end{array}$

Panel B: Regime shifts

Chow Breakpoint Test: 1989M11 1994M11 2002M11: F-stat 3.2 p-value 0.004

$\begin{array}{llll}\text { Panel C: } & 1989: 11-1994: 10 & 1994: 11-2002: 10 & 2002: 11-2007: 9 \\ \alpha & -0.32^{*}(0.13) & -0.28^{* *}(0.08) & -0.14^{*}(0.07) \\ \beta & 1.99^{* *}(0.61) & 1.92^{* *}(0.66) & 2.08^{* *}(0.25) \\ R^{2} & 0.34 & 0.32 & 0.35\end{array}$

Notes: Panel A and C. See notes to Table 1.

Panel B. Chow breakpoint test for the model in Panel A for the sample period: 1987:82007:09 


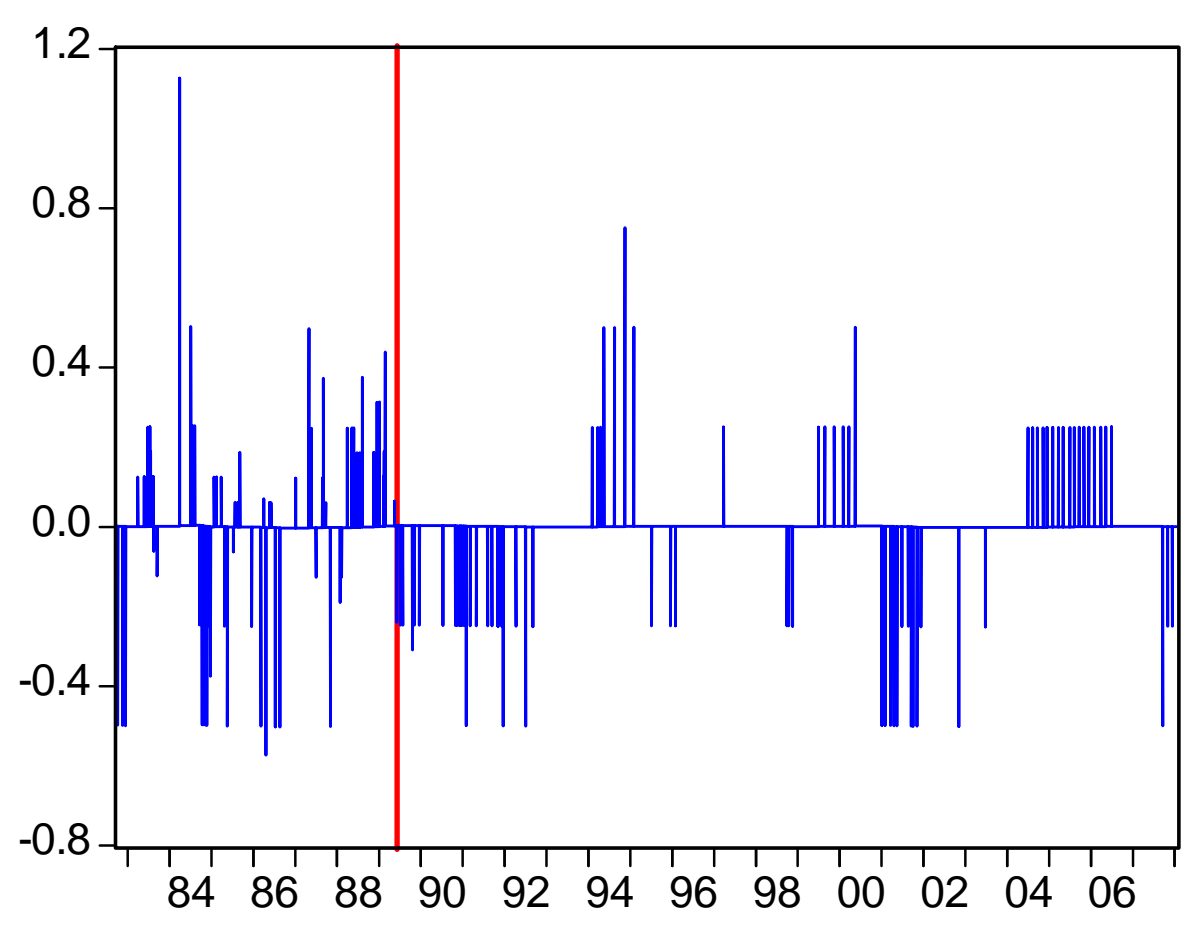

Fig. 1 Change in the (daily) fed target rate Note: Sample period: 1982:10-2007:12. 


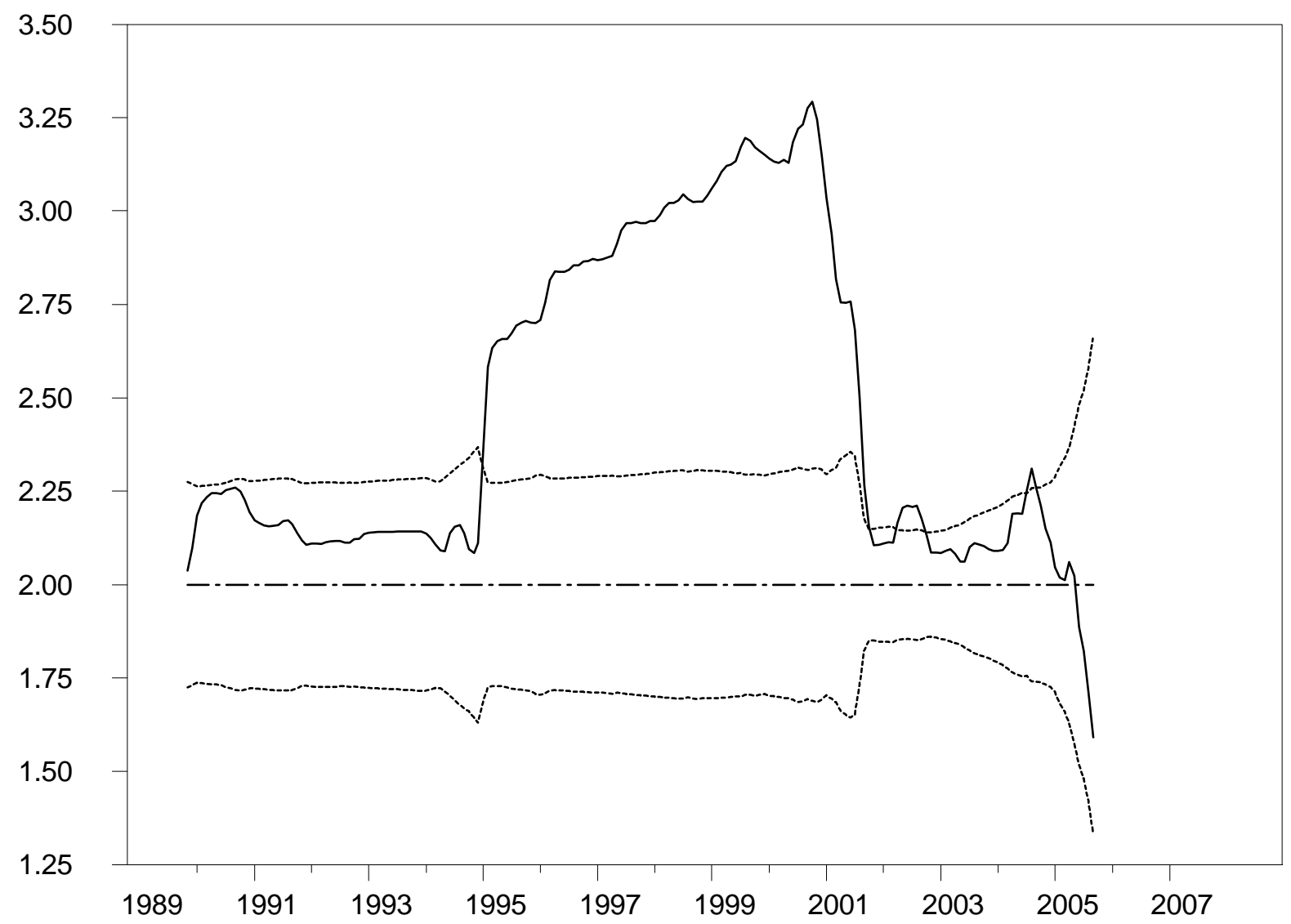

Fig. 2 Yield spread coefficient for different starting dates

Note: Result of the OLS regressions for the model $\left(r_{t+1}-r_{t}\right)=\alpha+\beta\left(R_{t}-r_{t}\right)+v_{t+1}$ ( $r_{t}=3$-month Treasury bill, $R_{t}=6$-month Treasury bill), sample period: 1989:112007:12, keeping the end of the sample fixed while moving the initial date one month ahead at every step. The dotted lines give the confidence interval at $5 \%$ for the null of $\beta=2$. 